\title{
Aggressive Behaviour among Elementary School Children in Bangalore: A Study on Gender and Grade Differences
}

\author{
Mala Murlidhar $^{1 *}$, Dr. Shailaja Shastri ${ }^{2}$
}

\section{ABSTRACT}

Aggression is a very commonly seen behaviour these days among school children. It is also one of the most prevalent behavioural aspects in children which cause a lot of concern in the present days. Aggression engulfs a wide spectrum of behaviours, which varies from covert to overt display of aggressive behaviours. The current study identified certain private schools in Bangalore city through purposive sampling method. With the help of teacher's checklist and Direct-indirect aggression scale (Bjorkvists,1992), a rating scale, rated by the class teachers, the researcher identified 366 children out of 38 schools, as displaying Aggressive Behaviours. The aim of the study was to understand the nature of aggression in elementary classes, and the different types of aggression displayed among boys and girls. This study identified the gender and grade differences in the display of aggression from grade 1 to grade 4 . There was a very significant difference in the aggression displayed by boys and girls, where boys were significantly higher in the display of direct aggression and there was no significant difference in verbal or indirect aggression in boys and girls. Boys in the sample followed a pattern on Direct, Verbal and indirect aggression, while girls followed a pattern of Verbal, Direct and indirect aggression. It was also seen that through the grade 1 to 4 , direct aggression was replaced by verbal aggression in the classrooms. The intensity of overall aggression was highest among boys and girls in grade 4 .

Keywords: Aggression, Elementary school children

Aggression in schools is one of the most pressing issues in the current generation and in schools. Aggression is generally defined as a behavioural act that results in hurting or harming others. Berkowitz (1981), defined aggression as a behaviour directed toward the goal of harming or injuring another living being, where the other person will be motivated to avoid the harm. This study identifies three different type of aggression using Direct-Indirect Aggression scale

\footnotetext{
${ }^{1} \mathrm{PhD}$ research scholar, Jain University, India

${ }^{2}$ HOD, Psychology Department, Jain University, India

*Responding Author

(C) 2016, M Murlidhar, S Shastri; licensee IJIP. This is an Open Access Research distributed under the terms of the Creative Commons Attribution License (http://creativecommons.org/licenses/by/2.0), which permits unrestricted use, distribution, and reproduction in any Medium, provided the original work is properly cited.
} 


\section{Aggressive Behaviour among Elementary School Children in Bangalore: A Study on Gender and Grade Differences}

(Bjorkvists, 1992). Direct, indirect and verbal aggression. Children engaging in direct aggression usually display it in terms of being physical, like hitting, kicking, punching, biting and so on. Indirect Aggression is shown by exclusions, social isolations, spreading rum ours, telling other's secret and so on. Verbal aggression is displayed by using bad words, abuses, threatening others, calling names and so on.

Aggression is also commonly viewed as being either proactive or reactive; covert or overt (Werner and crick, 2004). Children engaging in Proactive aggression typically use aggression to meet a goal. For example, if the child wants to have an object that belongs to another child, the proactively aggressive child will simply use aggression to take the object from the other child. These children use aggression to obtain social goals (Dodge, 1991). Reactively aggressive children on the other hand, do not seek to meet goals through aggressive behaviours. Instead they react negatively to perceived or actual threats and are easily irritated.(John. E. Lochman., et al 2009). This study takes into account the proactive ways of aggression, in all the three forms, i.e. direct, indirect and verbal aggression, where the aggressor has an intention of obtaining some tangible or intangible social goals in the process. And also reactive aggression, where a child in the intention of avoiding harm or securing oneself reacts in an aggressive way, which shows up as aggressive behaviour. Therefore in this study more than the intention or emotion behind it, the act of aggression, either proactively or reactively is considered.

Aggression is related to mental health problems in children, including externalizing disorders as Oppositional Defiant Disorder and Conduct Disorder, as well as internalizing problems with Depression and Anxiety (American Psychiatric Association, 1994). Aggression is therefore seen as a dysfunctional aspect of a Childs' development and growth. Aggression is seen as continuity from externalizing behaviour problems in childhood to risk taking behaviours in adolescence (Thompson et al, 2011. Brame et al, 2003). Therefore it becomes very crucial to identify the problem behaviours early in the school age and provide appropriate prevention mechanisms. Researchers in the west have shown that many of the aggressive symptoms and precursors of later aggressive behaviours and violence is evident in early childhood behaviours, which would be of milder forms (Tremblay, 2000). This and other studies have clearly indicated that aggression is a problem which continues through the adolescence and adulthood and hence it is just not a problem at that point of time.

Aggression in the schools is a very conspicuous phenomenon prevailing across cultures and race. This is so because in schools children get a lot of opportunities and exposure to different stimuli and cues to display their learnt behaviours or learn new ones. Developmental theory suggests that children's exposure to classrooms with high amount of aggression in elementary classes can have a stronger impact on the child aggressive behaviour, which they term as the primacy effect (Thomas et al, 2011). According to the social field theory model (Kellam et al, 1998), which 
argues for the primacy effect, says that it becomes very crucial at the school entry level for a child to face new behavioural demands like adjusting to peers, teachers, rules, regulations. Children who master these demands are able to move smoothly and develop appropriate social, emotional and cognitive abilities, compared to children who are not successful in accomplishing these adjustments in their early stages of schooling and continue the same maladjustment through their elementary school and further (Alexander, Entwisle, \& Dauber, 1993; Hamre \& Pianta, 2001; Perry \& Weinstein, 1998).

Howley et al (2000) reviewed several studies showing that large school are more likely than small schools to contain a high proportion of acting out students and greater behaviour management difficulties in classrooms. Similarly Stephenson and Smith (1989) found that the incidence of peer aggression increased as a function of school and classroom size and levels of socio economic disadvantage in the student body. In general, school poverty is positively correlated with the rates of student aggression (Battistich, Solomom, Kim, Watson, \& Schaps, 1995).Researchers have found that there are significant grade and gender differences in the prevalence of bullying and victimization (Olewus, 1991; Pepler et al., 1993). Specifically, bullying and victimization tends to decline with age. Boys tend to display more overt aggression and less indirect aggression than girls (Crick \& Grotpeter, 1995). Girls are more likely to use indirect aggression than overt aggression, probably because indirect aggression damages goals that are particularly important for girls (Crick \& Grotpeter, 1995).

Over the last two decades, structural features of the schools, such as large size, economic disadvantage among student body, and risky neighborhood conditions flanking school grounds, have been cited as variables associated with increased levels of student aggression (Colder, Mott, Flay, \& Levy, 2000;Howley, Strange, \& Bickel, 2000; Rutter, 1983). Research also suggests that exposure to grade school classrooms with many aggressive members may increase the risk for persistent aggressive behaviour problems (Barth, Dunlap, Dane, Lochman, \& Wells, 2004; Kellam, Ling, Merisca, Brown, \&Ialongo, 1998).

PREVALENCE IN INDIA: In the Indian scenario also we see an alarming proportion of children in schools displaying externalizing behaviours displayed through aggressive behaviour like, hitting, kicking, biting, scratching, destructive behaviours, teasing or verbally abusive language towards children and adults.

A study by Dutt, et, al (2013), in a rural area in West Bengal from classes $7^{\text {th }}$ to $9^{\text {th }}$, studied the magnitude, types and sex differentials of aggressive behaviour in school children, showed that $66.5 \%$ of the children were physically aggressive and $56.8 \%$ were verbally aggressive. Similarly a study by Shaikh et, al (2014) showed that, physical direct and indirect aggression was significantly more common in boys than in girls. 248 (71.5\%) of children were verbally 


\section{Aggressive Behaviour among Elementary School Children in Bangalore: A Study on Gender and Grade Differences}

aggressive in the previous month. Physical aggression increased substantially to from grade 7 (56.9\%) to grade 10 (84.6\%). They concluded that aggressive behaviours was both common in boys and in girls, with increasing trend of physical aggression from grade 7 to grade 10 .

All these trends in the Indian studies show that aggressive behaviour is highly prevalent in children, and hence need to study the factors which influence the aggressive behaviour in children, and an intervention or prevention program to control such behaviour. Therefore as the first step, this study tries to understand the patterns of aggressive behaviours in various types of schools and settings in private schools in Bangalore city, which can in the next phase lead to researches on factors leading to such behaviours in schools and prevention strategies.

The present paper focuses on the identification of children who display certain externalizing behaviours in the classrooms as observed by the class teachers and to identify gender differences and grade differences in the display of aggression. There is mounting evidence that school environments can contribute to the socialization and promotion of childhood aggressive behaviour problems. Hence it is becomes very important to understand the frequency and intensity of aggression seen in the schools and focusing more so on the elementary level, as several researches have indicated that early aggressive behaviour, has a higher chance of developing into later problem behaviours. And also there are very limited studies which focuses on this behaviour in the age group of 5-10 years of age. Hence this study intends to throw light on the prevalence of aggressive behaviour and its progression from grades 1 to 4 .

\section{REVIEW OF LITERATURE}

The review of Literature has been conducted to understand the prevalence of aggressive behaviours across different cultures and regions and also their impact on children in school. The following reviews has been divided into three categories:

1. Studies on the prevalence of aggression in schools

2. Studies on gender differences in aggression.

3. Indian studies on aggressive behaviours in schools.

\section{Studies on the prevalence of aggression in schools:}

Studies in this section has been selected to understand the literature available which helps the present study to get an overview of the trends seen in the past research on the prevalence of aggression in schools.

Nansel et al (2001), studied the prevalence of bullying behaviours among US youth and its association with psychosocial adjustment. Analysis of data from a representative sample of 15,686 students in grades 6 through 10 in public and private schools throughout the US who completed the WHO's health behaviour in school-aged children survey during the spring of

(C) The International Journal of Indian Psychology, ISSN 2348-5396 (e)| ISSN: 2349-3429 (p) | 154 
1998. The results showed that a total of $29.9 \%$ of the sample reported moderate or frequent bullying, as a bully (13\%), one who has bullied (10.6\%), or both (6.3\%). Males were more likely than females to be both perpetrators and targets of bullying. The frequency of bullying was higher among $6^{\text {th }}$ grade through $8^{\text {th }}$ grade students than among $9^{\text {th }}$ grade and $10^{\text {th }}$ grade students. Perpetrating and experiencing bullying were associated with poorer psychosocial adjustment $(\mathrm{P}<0.001)$.

A study by Anthony, Maria and Fred (1999), looked at the school bullies, victimization and aggressive victims, in early adolescence. The occurrence of bullying, victimization and aggressive victimization was documented in a sample of $5^{\text {th }}$ graders. Bullies comprised about $14 \%$ of the sample, whereas aggressive victims and victims comprised, respectively, $5 \%$ and $18 \%$. Bullying and aggressive victimization was positively related to youngsters' emotionality and activity and negatively related to peer popularity. Having friends and being liked by one's peers were protective factors against victimization, although the latter was more powerful than the former.

Kellam et al (1998) studied the effect of the level of aggression in the first grade class room on the course and malleability of aggressive behaviour in middle school. At the start of first grade, schools and teachers were randomly assigned to intervention or control conditions. Children within each school were assigned sequentially to classrooms from alphabetized lists, followed by checking to insure balanced assignment based on kindergarten behaviour. Children were followed through sixth grade, where their aggressive behaviours were rated by middle school teachers. Strong interactive effects were found on the risk of being highly aggressive in Middle school between the level of aggressive behaviour in first grade classrooms and each boy's own level of aggressive, disruptive behaviour in the first grade. The More Aggressive boys in higher aggression classes were at markedly increased levels of risk compared to aggressive children in lesser aggressive classes.

Wolker et al (2001), studied the prevalence and school factors of bullying and victimization of primary school children in England and Germany. A total of 2377 children in England and 1538 in Germany were questioned with an identical standard interview. In both countries the types of bullying to victimize others were similar: boys were more often the perpetrators, most bullies were also victims and most bullying occurred in playgrounds and the classrooms, and finally the ethnicity and SES showed only a weak association with bullying behaviour.

In a study by Camodeca et al (2002), bullying and victimization among school aged children and their stability and links to proactive and reactive children were assessed. At age 7, 236 children were rated on bullying and victimization using peer reports. At age 8, 242 children were rated again. 215 children (144 girls and 101 boys) were present at both points of time. Reactive and 
proactive aggression were rated by the teachers. The results show that bullies and bully/victims were both reactively and proactively aggressive, while victims were only reactively aggressive. A moderate degree of stability of bullying and victimization were found, with bullying being more stable than victimization. Boys were more often bullies than girls and more stable than girls in victimization. Stable victims and stable bully/victims were more reactively aggressive than their counterparts.

Bentley (1996), studied the prevalence and bully and victims problems in elementary schools and students beliefs about aggression. A total of 379, grades 4 to 6 students in Calgary were surveyed. The results of Bully/Victim questionnaire indicated that $21.3 \%$ were bullied and $11.6 \%$ bullied others "sometimes". Victims tended to be the youngest students in the sample. Both boys and girls were at risk for being bullied by both age-males and older students. Verbal abuse was the most common form of bullying and there was no significant association between gender and either direct or indirect forms of bullying. Bullies tended to be older in the grades and were mainly boys. Also results of the belief measure revealed that bullies were more likely than victims and students who were neither victims nor bullies to endorse certain aggression supporting beliefs.

Craig (1997), studied the relationship among Bullying, Victimization, Depression, Anxiety, and Aggression in Elementary School Children. The objective of the study was to examine, sex and grade differences among bullies, victims, bully/victims, and comparison children on physical, verbal, and indirect aggression and victimization and on depression and anxiety. 546 children in grades five through eight participated in the study. Children completed the Bully/ Victim Questionnaire, Depression inventory for children, Social Anxiety Scale, Relational Aggression and Victimization scale. The results indicated that across both grade levels, male bullies reported more physical and verbal aggression, than comparison groups. Male bullies and victims in the older grades reported more verbal aggression. For females, group differences in aggression did not emerge until older grades. There were only significant group differences on physical, verbal and indirect victimization.

Thomas and Bierman (2006), studied the impact of classroom aggression on the development of aggressive behaviour problems in children. The study followed a longitudinal sample of 4,907 children and examined the demographic factors associated with exposure to high-aggression classrooms, including school context factors and child ethnicity. The developmental impact of different temporal patterns of exposure to high aggression classrooms was evaluated on child aggression. Analyses revealed that African American children attending large urban schools that served socioeconomically disadvantaged students were more likely than other students to be exposed to high-aggressive classroom contexts. Hierarchical regression demonstrated the cumulative effects for temporal exposure, whereby children with multiple years of exposure

(C) The International Journal of Indian Psychology, ISSN 2348-5396 (e)| ISSN: 2349-3429 (p) | 156 


\section{Aggressive Behaviour among Elementary School Children in Bangalore: A Study on Gender and Grade Differences}

showed higher levels of aggressive behaviours after 3 years than children with primacy, less recent, and less chronic exposure, controlling for initial levels of aggression.

The above studies to understand the prevalence of aggression in children in schools, consistently shows that aggressive behaviours in children has tended to be a common phenomenon, where boys are more prominent in the behaviours of direct aggression. Both bullies and victims tended to be aggressive, either proactively or reactively. Studies have shown that with the increase in age, verbal abuse becomes the most prominent. It also indicates that aggressive behaviour increases with age and grade.

\section{Studies on Gender differences in aggression:}

This section of ROL focuses on the studies which gives us a broad understanding of the prevalence of gender differences in aggression in the past researches in this area.

A Meta analytical review by Archer John (2004), on sex differences in aggression in real world settings, where they covered self- reports, observations, peer report, and teacher observations on overall direct, physical, verbal and indirect forms of aggression, as well as trait anger (selfreport), revealed that direct, especially physical aggression was more common in males and females at all ages sampled across cultures. It occurred from early childhood showing a peak between 20-30 years. Higher female indirect aggression was limited to later childhood and adolescence. The overall pattern indicated males' greater use of costly methods of aggression rather than a threshold difference in anger.

Crick and Grotpeter (1995), studied the relational aggression, gender and socio-psychological adjustment. In their study, a form of aggression hypothesized as to be typical of girls, relational aggression, was assessed with a peer nomination instrument for a sample of 491 third through sixth grade children. Overt aggression (Physical and verbal aggression) and social-psychological adjustments were also further assessed. Results provided evidence for the validity and distinctiveness of relational aggression. They indicated as predicted that girls were significantly more relationally aggressive than boys were. Further they indicated that relationally aggressive children may be at a higher risk for serious adjustment difficulties.

Card et al (2008), studied the direct and indirect aggression during childhood and adolescence, through a meta-analytical review of gender differences, inter correlations and relations to maladjustment. The meta-analytical review of 148 studies examined the magnitude of gender differences, inter correlations between forms, and association with maladjustment. Results confirmed the prior findings of gender differences (favouring boys) in direct aggression and trivial gender differences in indirect aggression. Results also indicated a substantial correlation between these forms. The two forms also showed unique associations with maladjustment: 
Direct aggression is more strongly related to externalizing problems, poor peer relations, and low prosocial behaviours, and indirect aggression related to internalizing problems and higher prosocial behaviour.

Ostrov and Keating (2004), did an observational study of gender differences in pre-school aggression during free play and structured interactions. They observed 48 children from rural preschools in two different social contexts to test the hypothesis about the type (relational, physical, verbal, nonverbal), contextual independence, and sociometry of girls' and boys' aggressive tactics. They predicted and generally found that (1) girls displayed more relational aggression than boys while boys displayed more physical and verbal aggression than girla and that children received more physical and verbal aggression from male peers, and tended to receive more relational aggression from female peers, (2) behavioural observations of aggression corresponded with teachers' report of children's aggressive styles. (3) Aggression observed during free play predicted children's aggressive styles in a structured setting both at the individual and group levels.

Raymond et,al (2007), studied the gender differences in physical aggression in a population based survey of children before 2 years and after 2 years of age. The objective of the study was to test (a) gender differences in the prevalence of physical aggression in the general population of 17 month old children and (b) change in the magnitude of these differences between 17 and 29 months of age. Contrary to the differential socialization hypothesis, the results showed substantial gender differences in the prevalence of physical aggression at 17 months of age, with $5 \%$ of boys but only $1 \%$ of girls manifesting physically aggressive behaviours ona frequent basis. The results suggested that there is no change in the magnitude of these differences between 17 and 29 months of age.

Bjorkqvists et al (1992), studied the gender differences in regard to aggressive behaviour in a series of studies of school children of different age cohorts: 8yrs old ( $\mathrm{N}=85), 11$ year olds ( $\mathrm{N}=167)$ and 15 year olds ( $\mathrm{N}=127)$. Different types of aggressive behaviours were measured with peer nomination techniques, supported by self-ratings. The principle finding was that girls of the two older cohorts overall make greater use of indirect aggression, whereas boys tend to employ direct means. Previously, the main difference between the genders has been thought to be that boys use physical aggressive strategies while girls prefer verbal ones. They claimed that their studies suggest that the differentiation between direct and indirect strategies of aggression presents a more exact picture. Indirect aggressive strategies were not fully developed among the 8 year old age girls, but they were already prominent in the 11 year old girls.

Lagerspetz et al (1988), studied the gender differences in aggressive behaviours in 167, 11-12 year old school children, through peer rating techniques supported by self-ratings and interviews.

(c) The International Journal of Indian Psychology, ISSN 2348-5396 (e)| ISSN: 2349-3429 (p) | 158 
The principal finding was that girls made greater use of indirect means of aggression, whereas boys tended to employ direct means. Gender differences in verbal aggression was less pronounced.

Dorothy Seals and Jerry young (2003), studied the prevalence and relationship between bullying and victimization to gender, grade level, ethnicity, self-esteem and depression in the students of grades 7 and 8.Three survey instruments were used to obtain data from a convenience sample of 454 public school students. 24\% reported bullying involvement. Chi square tests indicated significantly more male than female bullying involvement, $7^{\text {th }}$ graders reported more involvement than did $8^{\text {th }}$ graders, and there were no statistically significant differences in involvement based on ethnicity. Both bullies and victims manifested higher levels of depression than did students who were neither bullies nor victims. There were no significant differences between the groups in terms of self- esteem.

The above studies on gender differences clearly show that there is a significant gender difference in the display of aggression, where most of the studies point out the significant difference in the display of direct aggression in boys compared to girls, whereas quite a few studies have indicated a small difference in indirect aggression for girls, but not as significant as for direct aggression. And there is not much difference in verbal aggression between both genders.

\section{Indian Studies on aggressive behaviour in children:}

This section of ROL focuses on the Indian researches on aggression in children in schools, which will help the current research to get an understanding of the past findings and to see if there are any gaps that could be addressed by the present study.

A study by Datta et al, (2012), studied the magnitudes and types of aggressive behavior in school children and the influence of age and sex on aggressive behaviorn a rural area of West Bengal. The participants were 161 boys and 177 girls of classes $7^{\text {th }}$ and $9^{\text {th }}$. The students were asked to complete a self-administered questionnaire indicating the types of aggressive behavior by them in the previous month (verbal/physical). They concluded that overall, $66.55 \%$ of the children were physically aggressive in the previous month: Boys 75.8\%, girls 58.2\%; 56.8\% were verbally aggressive: Boys $55.2 \%$ and girls $61 \%$. Verbal indirect passive aggression was more common among girls. With increasing age/class, physical direct aggression decreased while physical indirect passive and verbal indirect passive aggression increased. They concluded that aggressive behavior was common both among boys and girls. Research needs to be carried out on the factors associated with aggressive behavior and reasons for aggression.

Sharma (2012), studied the aggressive behavior in university students, and explored the relationship of it to the family environment. A total of 400 students (200 males and 200 females)

(c) The International Journal of Indian Psychology, ISSN 2348-5396 (e)| ISSN: 2349-3429 (p) | 159 
participated in the study. They were Indian students drawn from different departments of Himachal Pradesh University, Shimla. They were randomly selected from the classes. Direct and indirect aggression scales (DIAS) and the family environment scale were used to collect data. Each student was given the DIAS, to rate their peer under options they felt were relevant for him/her. Males rated males and females rated females. In the case of family environment scale, subjects were instructed to rate their own family environment. The results demonstrated that family environment affected aggressive behavior and reported some different correlates of aggressive behaviors of males and of females.

Bjorkqvist et al (2001), investigated the aggressive behavior of Indian adolescents of three age groups: 8, 11, and 15 years of age, using Direct and indirect aggression scale (DIAS). It consisted of adolescents from three religious groups from Delhi: Hindu, Muslims and Sikhs. Sex differences in the aggressive behavior was one focus of the study, besides age differences. 677 adolescents (284 girls and 393 boys) of three age groups and of different religious background: Hindu ( $\mathrm{n}=411)$, Muslim ( $\mathrm{n}=87)$, and Sikh $(\mathrm{n}=179)$. The results showed that there are relatively high levels of aggression among Sikh children aged 8 and 11, especially physical aggression among Sikh boys. The exceptionally low levels of female aggression were seen in the sample. The fact that sex differences in aggression appear to be greater in India than in the West. Perhaps Women in India are oppressed to such an extent that they have to suppress their aggression more than Western women.

A study by Fawwad Shaikh, Viveki, \& Halappanavar (2014), looked into the Physical and verbal aggressive patterns among school children in Urban area of North Karnataka. It included all 347 students of classes $7^{\text {th }}$ to $10^{\text {th }}$. The students were asked to answer by recall method, a selfadministered, pre tested, structured questionnaire indicating the types of aggressive behaviors by them in the past month. Physical active direct aggression and indirect aggression was significantly more common in boys than among girls. Overall $69.5 \%$ of children were physically aggressive in the previous month. $71.5 \%$ were verbally aggressive in the previous month. Physical aggression increased substantially from class $7^{\text {th }}(56.9 \%)$ to class $10^{\text {th }}(84.6 \%)$. They concluded that aggressive behaviours was both common in boys and in girls, with increasing trend of physical aggression from grade 7 to grade 10.

In the Indian context, there are a few studies on aggressive behaviour in children in the school setting, which shows that aggression is present among both boys and girls, physical more in boys and girls more on passive or indirect aggression. It also shows the gradual shift of aggression from overt to covert forms with age. 


\section{METHODOLOGY}

The study undertaken will help us to understand the prevalence of different forms of aggression across schools, and the gender and grade differences in them.

\section{Objectives of the study:}

- To study the different types of aggressive behaviours in elementary school children in Bangalore city.

- To study the gender differences in aggressive behaviours in elementary school children

- To understand the grade differences in the display of aggressive behaviours.

\section{Operational definitions:}

Aggression:

In this study aggression is broadly defined as an action intended to harm someone. It is studied under three types as defined by Bjorqvists et al (1992), direct aggression, indirect aggression and verbal aggression. As defined by the author, below given are the operational definitions for the same used for this study:

Direct aggression: Direct aggression in this study has been defined as a behaviour which causes physical harm or injury to another person. It includes all behaviours like kicking, hitting, shoving, pushing, tripping and so on. It can be both proactive and reactive aggression.

Indirect aggression: Indirect aggression in this study includes behaviours like social isolation, spreading rumours behind one's back, excluding one from the group, and spreading secrets of other person and so on. This behaviours as defined by the author, are indirect methods to cause harm by manipulating the social environment to hurt the target, sometimes without the aggressor being identifiable.

Verbal aggression: Verbal aggression according to the author includes behaviours such as yelling, teasing, using bad words, hurtful remarks, making threats and so on.

School Aggression: This is defined by the researcher for the study purpose as the behaviours displayed by children in schools in the classrooms as observed by teachers, which fall into any one or all of the above categories of aggression.

Children: In this study the term 'children' refers to elementary school children, that is, children who are studying in the grades 1 to 4 in the selected schools.

\section{Research Design:}

To select the sample population and to understand the aggressive behaviours of children, the following methodology was implemented. The study was divided into two phases. 


\section{PHASE 1:}

\section{Sample selection process of the schools:}

The objective of this phase was to select the schools across Bangalore city from which the sample of children displaying aggressive behaviours would be selected. The following was the process followed for the same:

\section{Inclusion criteria for the selection of schools:}

The schools selected for this phase of the study would be:

- $\quad$ The schools selected would be private schools in Bangalore city.

- $\quad$ The schools selected would be from State, CBSE, and ICSE syllabus curriculum.

- The schools will be included in the study on the basis of permission given by the school management to conduct the research.

- $\quad$ The schools will be located within the limits of Urban Bangalore.

Exclusion criteria for the selection of schools:

The schools that would be selected for the study would not be:

- $\quad$ The schools would not be government or government aided institutions.

- $\quad$ The schools will not be situated in rural areas or outside the limits of Bangalore city

- The schools which do not give permission will not be included in the sample of schools for the study.

\section{Procedure of phase 1:}

To select the sample schools of the phase 1, the researcher divided the whole of Bangalore city into North zone and South zone, so that geographically the identification of schools to seek permission is well spread across the whole city. The researcher adopted purposive sampling method to identify equal number of schools in both the zones with the inclusion and exclusion criteria in place. With this process, there were 90 schools which was identified to be approached for seeking the permission. Out of the 90 schools identified, the researcher could get permission in 38 schools to conduct the research. In these 38 schools, 30 schools which gave permission were from the south zone and eight schools belonged to the North zone of Bangalore.

\section{PHASE 2:}

\section{Sample selection of children who display aggressive behaviour:}

The objective of this phase was to select the children who display certain aggressive behaviours in the classrooms through teachers' observation and rating scale.

\section{Inclusion criteria:}

Children selected to be a part of this study would be:

- Children who would be selected for the study would be from the elementary classes, ie, from class 1 to class 4 .

- Both boys and girls would be selected for the study.

- The children would be selected on the basis of teacher's observation of the display of aggressive behaviours.

(c) The International Journal of Indian Psychology, ISSN 2348-5396 (e)| ISSN: 2349-3429 (p) | 162 


\section{Aggressive Behaviour among Elementary School Children in Bangalore: A Study on Gender and Grade Differences}

\section{Exclusion criteria:}

- Children who are not in the elementary classes (below class 1 or above class 4 ), will not be a part of the study.

- Children who have disabilities like learning disability, dyslexia, ADHD, autism, mental retardation, slow learners, and who are reported by the teachers, will not be included in the study.

- Children who are physically handicapped or any other major illness will not be included in the study.

- Children who are on any psychiatric medication, as reported by the teachers, will not be included in the study.

\section{Procedure of phase 2:}

In this phase, the researcher approached the schools in which permission was given, to meet the teachers of the respective schools of classes 1 to 4 . The researcher met the class teachers either one on one or in a group, to explain them the study purpose and the objective and their role in identifying and rating the children who display aggressive behaviours. The teachers were provided with a checklist and explained each behaviour in the checklist to observe and identify children of their respective classes. The teachers were instructed to observe the children's behaviour in the class for a week and then to shortlist the children who would be displaying six or more behaviours consistently for more than 3 months, out of the 24 behaviours in the checklist. The teachers were also instructed to observe and notice both girls' and boys' behaviours in their classes with the checklist in mind. They were also briefed about the inclusion and exclusion criteria's for selecting the children. They were told to identify and select as far as possible, one girl, for one boy identified and selected, so that in the total sample both boys and girls are equally represented.

After this, the researcher met the class teachers again after one more week, as decided. The teachers' who had identified and selected the children in their classes were provided with a rating scale, with the same behaviours to mark the frequency and intensity, with the rating from 0 to 4 , i.e.from never to always, to mark for each child identified and selected. The teachers who had not identified or selected were given one more weeks' time to complete the activity. After the teacher rated each child identified on the rating scale, the researcher then shortlisted the children who displayed $25 \%$, or more than $25 \%$ of the total score, i.e.a score of 24 or more on the total score of 96 . This procedure was repeated in all the selected schools.

With this procedure, the teachers in all the 38 schools which had granted the permission, had identified and marked 423 children in elementary classes as displaying certain aggressive behaviours. Out of which, the researcher selected $366(\mathrm{n}=366)$, as the final sample, where 23 (5\%), of the teachers selection were rejected as they were not complete. And 34 (8\%), of the 


\section{Aggressive Behaviour among Elementary School Children in Bangalore: A Study on Gender and Grade Differences}

sample was rejected as the children selected were below the $25 \%$ cut off level to be included in the sample.

The final sample size was $n=366$, from 38 private schools in Bangalore city. Below is the table showing the distribution of schools in North and South zones respectively and the average number of children per each stream selected based on the curriculum.

Table 1.1: Showing the number of children and schools selected from Bangalore city

\begin{tabular}{|c|c|c|c|}
\hline $\begin{array}{c}\text { BOARD OF } \\
\text { AFFILIATION }\end{array}$ & $\begin{array}{c}\text { NO OF SCHOOLS } \\
\text { PER BOARD }\end{array}$ & $\begin{array}{c}\text { AVG NO OF } \\
\text { CHILDREN PER } \\
\text { SCHOOL }\end{array}$ & TOTAL \\
\hline CBSE & 17 & 11 & 186 \\
\hline ICSE & 9 & 8 & 72 \\
\hline STATE & 12 & 9 & 108 \\
\hline & & & 366 \\
\hline
\end{tabular}

The table above shows that in the 38 schools in which permission was granted, there were totally 17 CBSE schools, 9 ICSE schools and 12 State board schools. It can be seen that the number of schools with CBSE board is the highest followed by State and ICSE. This is so, since the distribution of the school across Bangalore city also follows the same pattern.

\section{Techniques of Assessment:}

\section{- The behaviour checklist for teachers:}

This checklist provided by the researcher to the teachers contained a list of 24 behaviours of children which are extracted from the scale described below. These checklist behaviours would help class teachers to observe the children in their classes for some days and then to rate them on the rating scale provided.

\section{- $\quad$ Direct- Indirect Aggression scale (DIAS), by Bjorkqvist, et al., (1992):}

This scale investigates the aggression of a child as rated by the peers or teachers. This study would use a teacher rated scale, which is a likert type scale from 0 to 4 , where 0 is never and 4 is always. The test-retest value and inter-rater reliability is not assessed for this scale. The range of internal consistency is 0.78 to 0.96 . The sub scales are:

Direct physical aggression- This subscale has 7 items like, pushing, shoving, kicking shoving and so on.

Direct verbal aggression- This subscale has 5 items which would include behaviors like yelling, insulting, teasing, calling names, and threatening.

Indirect aggression- This subscale has 12 items like taking revenge, ignoring others, gossiping, planning to bother others, telling secrets and so on. 


\section{RESULTS}

In this section, the results are divided into three levels:

a) To identify different types of aggressive behaviours in children in the overall sample

b) To analyse the gender differences in the display of aggressive behaviours in children

c) To analyse the grade-wise differences in the display of aggressive behaviours.

(a) The focus of the first section of the results is to identify different types of aggressive behaviours in elementary school children.

(i) The presence of the different types of aggression namely direct, indirect and verbal were analysed for the total sample population, $\mathrm{n}=366$. The graph below shows the results.

Graph 1.3: Showing the presence of direct, indirect and verbal aggression in the overall sample

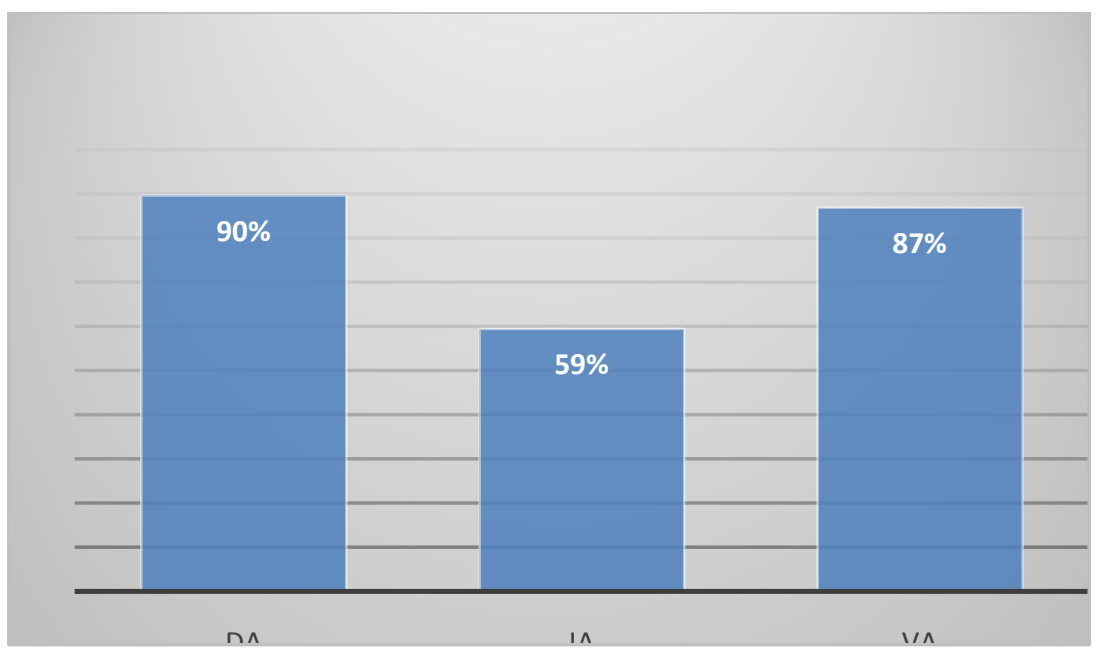

In the above graph showing the overall prevalence in the sample, it is seen that direct aggression is the highest(90\%), verbal aggression(87\%) is closely following the direct aggression, while indirect aggression(59\%) is the least prevalent.

(ii) Most prevalent behaviours seen in classrooms: Presence of aggressive behaviours were also explored as a series of behaviour pattern which is very commonly seen in class rooms. The top five behaviours seen in the order of intensity are shown in this chart shown below. The presence of the mentioned behaviours are shown ascending order.

(c) The International Journal of Indian Psychology, ISSN 2348-5396 (e)| ISSN: 2349-3429 (p) | 165 
Aggressive Behaviour among Elementary School Children in Bangalore: A Study on Gender and Grade Differences

Graph 1.4: Showing the commonly seen behaviours in class rooms

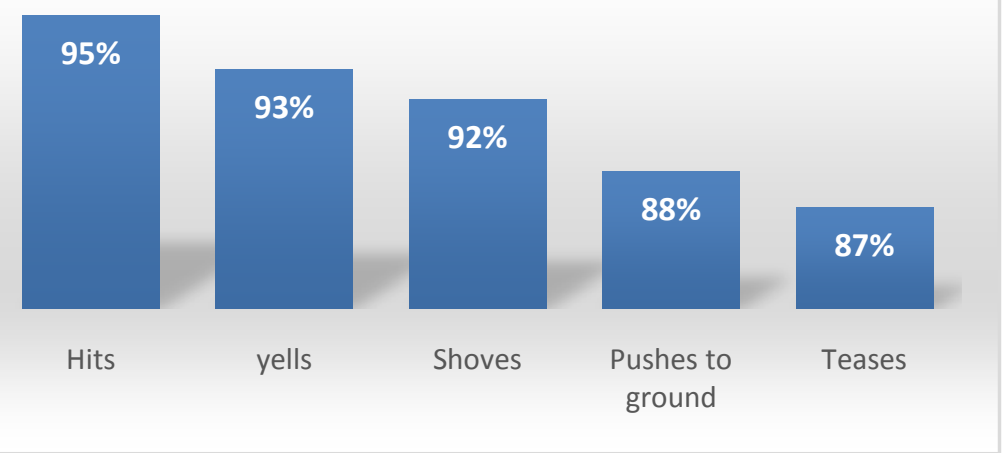

The above chart shows the top five behaviours present in the schools, seen in the classrooms in terms of intensity and frequency. Hitting takes the first place with nearly $95 \%$ of the students are reported by the teachers as displaying the mentioned behaviour. It is closely followed by yelling (93\%), Shoving (92\%), Pushing to the ground (88\%), and Teasing (87\%).

(b) The second part of the result section was framed to analyse the gender differences in the display of different types of aggressive behaviours in children.

(i) Difference in the overall aggression displayed among boys and girls in the sample population:

The chart below shows the differences in the overall aggression( direct, indirect and verbal aggression) among boys and girls, rated by the teachers as 'often' according to the rating scale DIAS (Direct- Indirect Aggression Scale, Bjorkquists,1992) in the total sample(n=366).

Graph 1.5: Showing the differences in the overall aggressive behaviours among boys and girls in the sample population

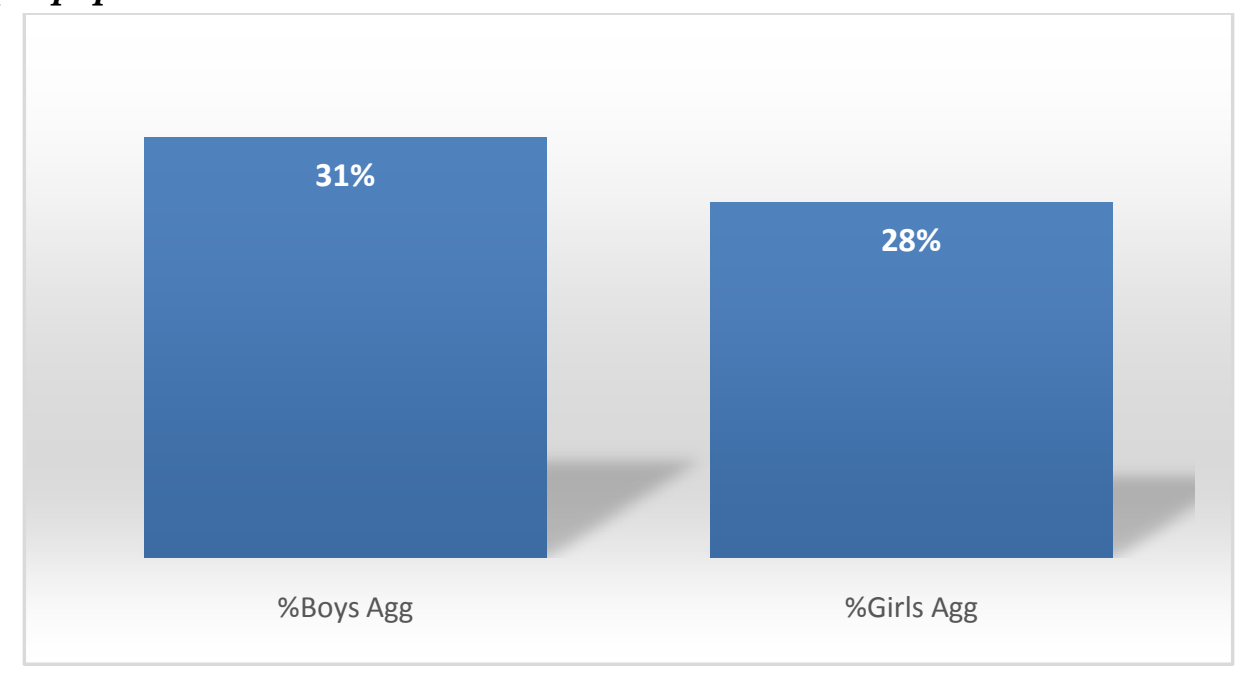

(C) The International Journal of Indian Psychology, ISSN 2348-5396 (e)| ISSN: 2349-3429 (p) | 166 
The chart above displays the difference in the presence of aggression in boys and girls. 31\% of the boys are seen to be displaying aggression 'often' in the class room, whereas $28 \%$ of girls are seen doing the same. The differences seen is minimal among boys and girls in the sample.

(ii) $\quad$ t-test: A t-test was administered to test if there are significant gender differences in the display of direct, indirect and verbal aggression among boys and girls in the population using an independent sample t-test

Table 1.6: Showing the results of the t-test

\begin{tabular}{|c|c|c|c|c|c|}
\hline Variables & Gender & $\mathbf{N}$ & Mean & S.D. & "t" \\
\hline \multirow{2}{*}{ Direct Aggression } & Female & 69 & 11.96 & 5.98 & \multirow{2}{*}{$4.694 * *$} \\
\hline & Male & 297 & 15.54 & 5.65 & \\
\hline \multirow{2}{*}{ Indirect Aggression } & Female & 69 & 16.88 & 9.83 & \multirow{2}{*}{1.075} \\
\hline & Male & 297 & 15.48 & 9.77 & \\
\hline \multirow{2}{*}{ Verbal Aggression } & Female & 69 & 9.33 & 4.11 & \multirow{2}{*}{1.046} \\
\hline & Male & 297 & 9.90 & 4.03 & \\
\hline
\end{tabular}

** $\mathrm{p}<0.01$

The above table shows that there is a significant difference in the scores for direct aggression for girls $(\mathrm{M}=11.96, \mathrm{~S} . \mathrm{D}=5.98)$ and boys $(\mathrm{M}=15.54, \mathrm{~S} . \mathrm{D}=5.65)$ conditions; $\mathrm{t}=4.964, \mathrm{p}=0.01$. The results suggest that Boys and Girls are significantly different in the display of direct aggression, where boys are seen to be displaying significantly higher direct aggression than girls. The mean differences however show that in indirect aggression, girls are marginally higher, which is not significant. While on verbal aggression boys are marginally higher, which again is not significant.

\section{(c) Grade level differences in the display of aggression:}

The children in all the 38 schools have been classified class wise from grade 1 to grade 4, to analyse the grade differences in the forms of aggression (direct, indirect and verbal) and intensity of aggression shown at each level among boys and girls.

The table below shows the number of boys and girls selected in each grade.

Table 1.7

\begin{tabular}{|l|l|l|l|l|}
\hline Students & Grade 1 & Grade 2 & Grade 3 & Grade 4 \\
\hline Boys & 65 & 95 & 74 & 63 \\
\hline Girls & 16 & 26 & 14 & 13 \\
\hline Total & 81 & 121 & 88 & 76 \\
\hline
\end{tabular}

As seen in the table above, maximum number of boys and girls have been selected by the teachers' in grade 2 . The table above clearly shows that the children selected for the display of aggression is least in the grade 1 , highest in grade 2, decreases in grade 3 and further decreases in grade 4.

(C) The International Journal of Indian Psychology, ISSN 2348-5396 (e)| ISSN: 2349-3429 (p) | 167 
(i) Grade differences in the display of the of overall aggression in the total population: The chart below shows the grade differences in the overall aggression (direct, indirect and verbal), in the total population $\mathrm{n}=366$.

Chart 1.8: Showing the grade differences in aggression in the total population

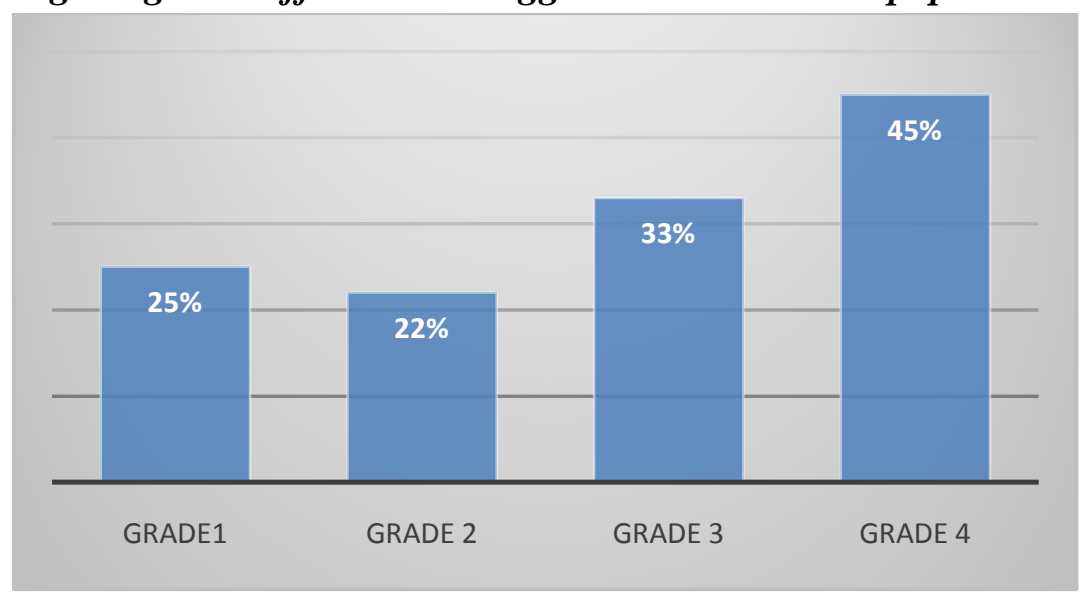

This chart shows the grade differences in the display of overall aggression in the classrooms, rated at an intensity of 'Often' according to the DIAS (Direct-Indirect Aggression Scale, Bjorkquists, 1992) rating scales given to the teachers. It can be seen that intensity of overall aggression in the total population increases sharply in grades 3 and 4 .

(ii) Grade differences in the overall aggression among boys and girls:

The chart given below shows the grade differences from grade 1 to grade 4 in the overall aggression (direct, indirect and verbal), among boys and girls separately.

Chart 1.9: Showing the grade wise gender differences in the overall aggression

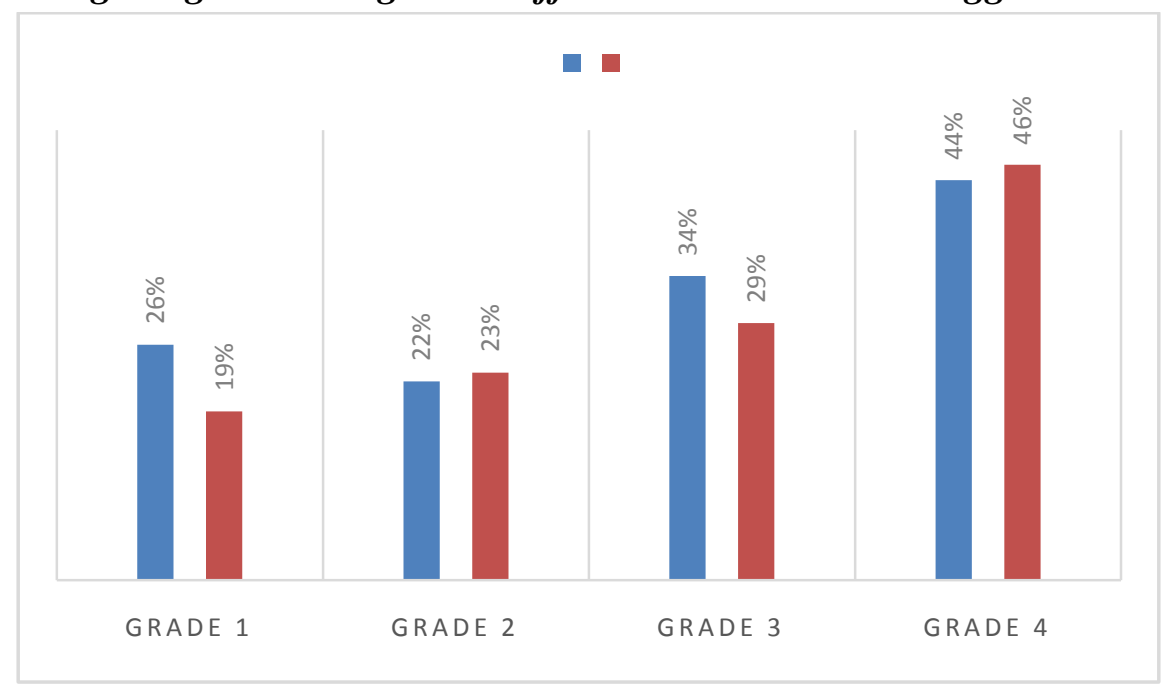

(C) The International Journal of Indian Psychology, ISSN 2348-5396 (e)| ISSN: 2349-3429 (p) | 168 
The above chart shows the grade differences in the overall display of aggression in the classroom, rated at an intensity of 'often' by the class teacher, from grade 1 to grade 4 . The cumulative graph clearly shows that the intensity of overall aggression of children in classrooms steadily increases from grade 1 to grade 4 in both boys and girls. There is a very minimal difference in the intensity of aggression from grade 1 to grade 4 among boys and girls.

\section{Grade wise differences in the types of aggression (direct, indirect and verbal) displayed in the overall sample:}

The graph below shows the grade wise differences in the various forms of aggression displayed by children in the total population $(\mathrm{n}=366)$.

\section{Chart 1.10: Showing the grade differences in the types of aggression displayed}

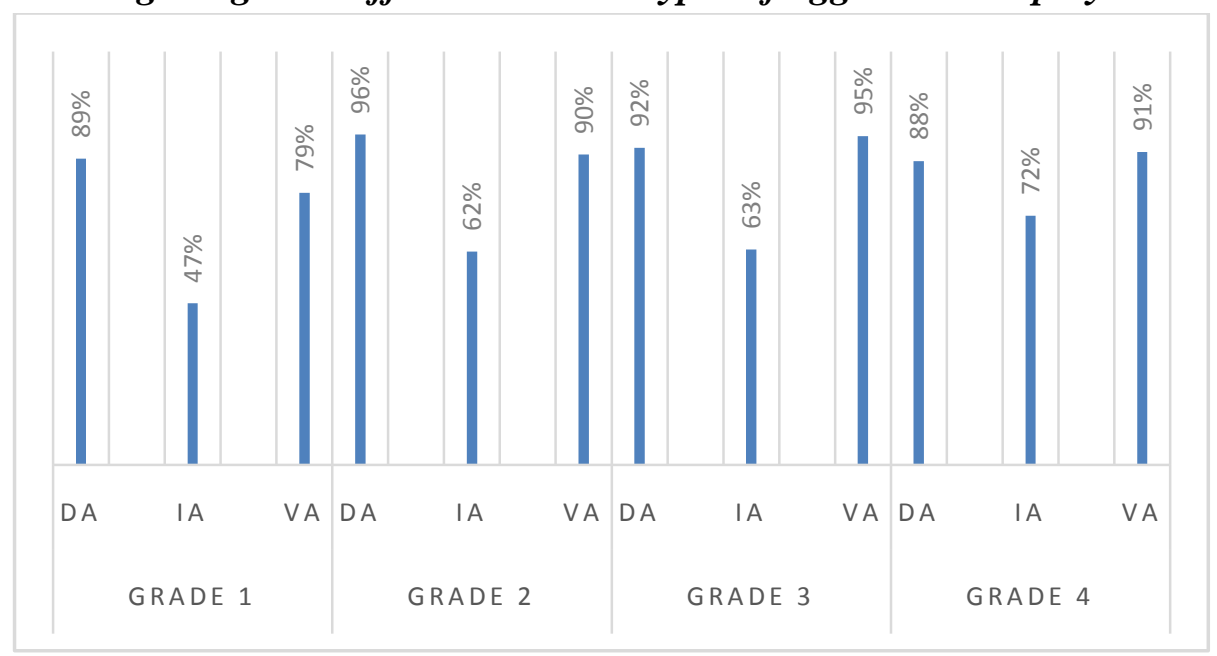

The above graph shows the prevalence of difference forms of aggression in terms of intensity and frequency seen and its changes through the grades. It is clearly seen that direct aggression is the highest in grade 1 and grade 2, grade 2 being the highest in direct aggression. Through the grades from 2 to 4 , we can see a slight decrease in the direct aggression form and a marginal increase in the verbal aggression. Also one more notable difference is in the display of indirect aggression, where through grades 1 to 4 , the intensity of indirect aggression slowly increases, and it is highest in grade 4 .

(iii) Grade wise differences in types of aggression(direct, indirect and verbal) among boys and girls in the sample:

The chart below shows grade wise differences from grade 1 to grade 4, in the types of aggression displayed (direct, indirect and verbal), among boys and girls separately. 


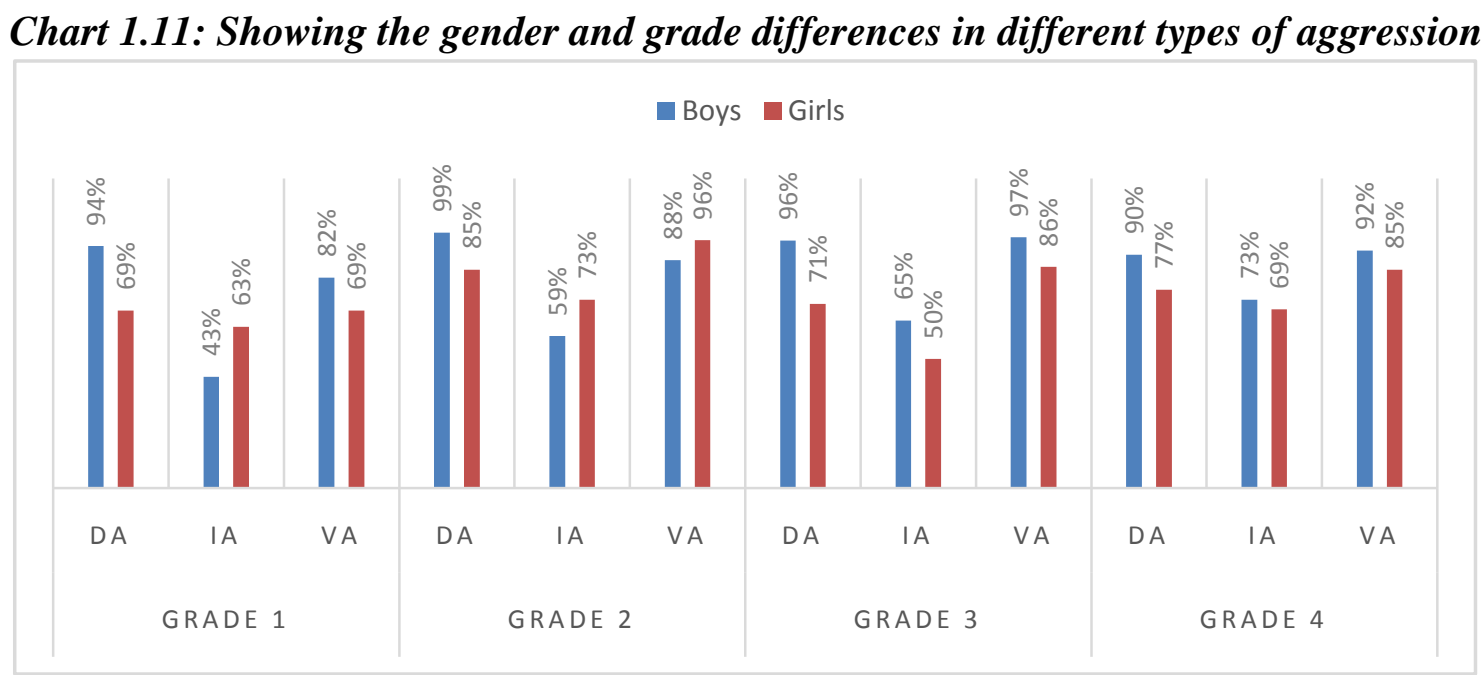

The above chart shows the grade differences in the intensity of aggression and in their forms among boys and girls separately. It is seen that for boys direct aggression is the highest prevalent form in all the grades. For girls, verbal aggression form is the highest prevalent in all the grades. In the transition from grade 1 to grade 4 , for boys it is seen that direct aggression form gradually and marginally decreases and verbal aggression increases in grade 3 and grade 4 . In girls, the transition is not much visible, although it is noticed that verbal aggression form, is the highest through all the grades, and indirect aggression is highest in grade 2 . Therefore for girls the transition from grade 1 to grade 4 is not very clear.

\section{DISCUSSION}

The present study on the prevalence of different types of aggression in boys and girls in different types of school and by grades through grade 1 to grade 4 were analysed to understand the present trends in aggressive behaviours among school children. 366 children were selected as sample of children who display aggressive behaviours from 38 schools in Urban Bangalore private schools through a teacher's checklist and rating scale.

In the overall sample studied it is seen that direct aggression in classrooms is the most prominent form of aggression in schools, followed by verbal, and indirect is the least seen form. It is also seen that the most prevalent behaviours in order of intensity and frequency are hitting, Yelling, Pushing, pushing to the ground, and teasing in the same order. This shows that direct aggression is the highest prevalent, closely followed by verbal forms. The results is also supported by a study by Shaikh et al (2014) in a North Karnataka district, which shows that physical active direct aggression like hitting, slapping, pushing etc was significantly more common in boys than among girls. The findings are also in line with the thinking of Bjorkqvist et al (1992) that the trend in aggressive behaviours appears in the order of physical direct, verbal and indirect and passive aggression. As argued by Piaget (1932), one of the first psychologist to study the stages of development of cognitive abilities in people, that sensory-motor stage is the

(C) The International Journal of Indian Psychology, ISSN 2348-5396 (e)| ISSN: 2349-3429 (p) | 170 


\section{Aggressive Behaviour among Elementary School Children in Bangalore: A Study on Gender and Grade Differences}

first to develop, and children respond to their environment and stimuli through a very simple ways of focusing on their motor skills. By the end of final stage (adolescence) they would have developed complex reasoning and abstract thoughts. Therefore it seems logical that physical ways of showing power, disapproval, and anger comes as an instinctual drive. And in alignment with this process, as seen in the present paper, hitting, pushing, pulling is the most prevalent behaviours seen in the elementary class rooms and later comes verbal and indirect forms.

\section{Gender differences in aggression:}

It is seen that there is significant difference ( 0.01 level) in the display of direct aggression, where boys are higher in the display of direct aggression than girls and there is not as much significant difference in the display of indirect and verbal aggression in both boys and girls. This finding is also supported in a study by Bjorkqvist et al (1992), at the age cohort of 8 years, there is a significant difference between the genders on direct aggression, boys displaying more of it. On indirect aggression, there was only a slight (insignificant) difference, the girls scoring somewhat higher. In the same study, Bjorkqvists (1992), in the age cohort of 15 years, found that boys again scored significantly on physical aggression, while girls in this age scored significantly higher in indirect aggression. This shows that on indirect aggression, although there is a tendency for girls to be more on indirect aggression, it might start much later in their age through their pre adolescence and adolescence. In a meta- analytic review of 148 studies on child and adolescent direct and indirect aggression by Card et al (2008), results confirmed the prior findings of gender differences favouring boys in direct aggression and trivial gender differences in indirect aggression. . A similar study by Datta et al (2012), studying the magnitude and the types of aggressive behaviours in school children also shows that physical direct aggression is commonly seen in boys, whereas girls are more into display of verbal indirect passive aggression.

These studies support our study, where there is no significant difference in the gender in both verbal and indirect aggression, but a significant difference in boys in the display of direct aggression. The researcher has the opinion that from a socio cultural point of view, it can be seen that girls are trained to be less overt and timid, compared to boys. It is always expected that girls do not exhibit their anger or disapproval in an overt way. Therefore being physical or showing overt forms of aggression is not an approved and accepted behaviour for girls. Therefore, maybe since younger ages girls are more prone to use milder or covert forms of displaying aggression and hence the significant difference seen in only physical aggression form.

\section{Aggression studied across grades from 1 to 4:}

In the selection of students through grades, the least numbers selected are from grade 1, the numbers selected sharply increase in grade 2, where it is the highest in prevalence, slowly and steadily decrease in grade 3 and grade 4 . With the pattern seen above it could be understood that as and when a child enters grade 1 from nursery classes, everything seems new to the child, and

(c) The International Journal of Indian Psychology, ISSN 2348-5396 (e)| ISSN: 2349-3429 (p) | 171 


\section{Aggressive Behaviour among Elementary School Children in Bangalore: A Study on Gender and Grade Differences}

hence the children would be more restrained in their behaviours. The first year of schooling therefore shows lesser prevalence of aggressive behaviours in children. By the second year children seem to be accustomed to the environment and less inhibited in displaying their negative behaviours and therefore the number of children selected for displaying aggressive behaviours are highest in grade 2. By the age of grade 3 and grade 4, through age, certain socially appropriate behaviours are learnt and hence children learn self- regulation. Therefore the gradual decrease in the numbers are seen naturally through grade 3 and 4 . As seen in chart 1.9, the intensity of aggression is highest is in grade 4, although the number of children selected for displaying aggressive behaviours is the least in grade 4, which is an interesting feature to note. The reason perhaps can be attributed to the reason that, although most children learn to inhibit their instinctual behaviours through age, few of them who do not learn socially appropriate behaviours for various reasons are more disposed to increase their intensity of aggressive behaviours to gain their status or position among peers. This is actually quite an alarming trend, because children learn to use their strength in a negative way and get sucked in it.

In the overall aggression among boys and girls through grades 1 to 4 , it is clearly understood that the intensity of overall aggression gradually increases in both boys and girls through the grades and it is seen at the highest intensity (rated as 'often' by the teachers) at grade 4 . This can be attributed to the slow increase in the verbal and indirect aspects of aggressions in grades 3 and 4 in both boys and girls. This shows that a small percentage of children who continue to be aggressive through grades increase their problem behaviours in intensity as compared to previous grades which is a detrimental feature to note (Cummings et al 1989, Nagin D.S and Tremblay et al, 2003, Thompson et al, 2011, Brame et al. (2003), In the category of grade segregation of aggressive behaviours, it is very well seen that in grades 1 and 2, direct aggression is seen as the most prominent form of aggression in boys, whereas verbal aggression is the prominent form of aggression for girls. It is also seen that in classes 3 and 4, verbal aggression becomes the prominent form followed by direct aggression. This is supported by similar findings from other researches, Bjorqvists et al (1992), Datta et al (2012), Craig (1997).

Also comparatively, the prevalence of indirect aggression form slowly increases through grade 1 to grade 4.As quoted by Bjorkqvists et al (1992), indirect aggression is dependent on maturation, a certain level of both verbal and social skills is needed. Therefore for children who are in elementary classes, it is seen developmentally that direct aggression is the earliest to develop, then develops verbal aggression, as and when their verbal abilities develop. The last to develop would be the indirect aggression when their social skills development starts. As seen in the analysis, the highest number of children selected for the display of aggressive behaviours are seen in grade 2 classrooms, and physical aggression in this grade is the highest compared across all grades. When seen in comparison, boys and girls of class 2, we see that boys in class 2, most prominently use direct aggression, while for girls, they are high on the display of both verbal and 


\section{Aggressive Behaviour among Elementary School Children in Bangalore: A Study on Gender and Grade Differences}

indirect aggression and also girls through all the four grades are higher on verbal aggression and indirect compared to physical aggression. This clearly shows that on the aspects of social maturation in the early ages, girls overtake boys of their age. By grade 2, girls are able to use indirect forms of aggression more frequently and with higher intensities compared to boys of grade 2. This is supported by other studies which also found that physical aggression in boys are more common and verbal aggression in girls Datta et al (2012), Craig (1997).

\section{CONCLUSIONS}

- In the present study it can be seen that in the teacher's selection of aggressive behaviours in the classrooms, boys are selected more in numbers than girls which shows that boy's display of aggressive behaviours is more noticeable by the teachers in the class.

- There is a significant gender differences in the display of direct aggression form, where boys are higher in direct aggression (0.01 level). In verbal and indirect forms of aggression there are no significant gender differences.

- Also it is very clearly seen that in the schools across categories, for boys, the display of direct aggression takes the most prominent form of aggression, followed by verbal and indirect aggression.

- Girls follow the pattern of verbal aggression, direct aggression and indirect aggression.

- Indirect aggression is the least seen form in the class rooms by the class teachers.

- Grade wise analysis of aggressive behaviours clearly shows that the direct aggression form in grade 1 gradually changes to verbal aggression through grade 4 .

- Although the number of students chosen by teachers as displaying aggressive behaviours in classrooms decrease consistently from grade 1 to grade 4, highest number of children selected in class 2, and the lowest number in class 4 , the overall intensity of aggressive behaviours among both boys and girls consistently increase from grade 1 to 4 , and is highest at the grade 4 .

It can be concluded that the problems of aggressive behaviours in children as noticed by the class teachers are seen in all grades and the intensity of the problem increases through grades if not intervened at the right time. It is an all pervading problem in school these days. Hence the need for identifying the problem and focusing on school based interventions to reduce the same at the school entry levels.

\section{Acknowledgments}

The author appreciates all those who participated in the study and helped to facilitate the research process.

\section{Conflict of Interests}

The author declared no conflict of interests.

(c) The International Journal of Indian Psychology, ISSN 2348-5396 (e)| ISSN: 2349-3429 (p) | 173 


\section{BIBLIOGRAPHY}

Alexander, K,L., Entwisle, D,R., Dauber, S, L (1993). First grade classroom behaviour: Its shortterm and long-term consequences for school performance. Child Development. Vol 64; 801-814.

American Psychiatric Association, 1994. Diagnostic and Statistical Manual of Mental Disorders ( $4^{\text {th }}$ Ed.).

Anitha, Sharma (2012). Aggressive behaviors in university students: The role of family environment. Advances in Social Sciences, Vol 2, No 1.

Archer, John (2004). Sex differences in aggression in real world settings: A Meta-Analytical review. Review of General Psychology, vol 8(4), 291-322.

Baillargeon, Raymond, H., Zoccolillo, Mark., Keenan, Kate., Cote, Sylvana., Perusse, Daniel., Wu, Hong-Xing., Boivin, Michel., Tremblay, Richard, E. (2007). Gender differences in physical aggression: A prospective population based survey of children before and after 2 years of age. Developmental Psychology, vol 43(1), 13-26.

Barth, J, M., Dunlap, S, T., Dane, H., Lochman, J, E., Wells, K, E (2004). Classroom environment influences on aggression, peer relations, and academic focus. Journal of School Psychology; Vol 42: 115-133.

Battistich, V., Solomon, D., Kim, D., Watson, M., Schaps, E (1995). Schools as communities, poverty levels of student populations and student attitudes, motives and performance: A multilevel analysis. American Educational Research Journal. Vol 32, pp. 627-258.

Bjorkqvist, K., Lagerspetz, K, M., \& Osterman, K. (1992). The Direct and Indirect Aggression scale (DIAS). Finland: Abo Akademi University, Department of Social Sciences.

Bjorkqvist, K., Osterman, K., Oommen, T, K., \&Lagersprtz, K, M, J (2001). Physical, verbal, and indirect aggression among Hindu, Muslim and Sikh Adolescents in India. In M. Martinez (Ed). Prevention and control of aggression and the impact on its victims. Kluwer Academic Publisher.

Bjorkqvists, K., Lagerspertz, K, M., Kaukiainen, A (1992). Do girls manipulate and boys fight? Developmental trends regarding direct and indirect aggression. Aggressive Behavior, Vol $18 ; 117-127$.

Bobby, Brame., Daniel, S,Nagin., Richard,E,Tremblay(2003). Developmental trajectories of physical aggression from school entry to late adolescence. Journal of child psychology and psychiatry, Vol; 42 (4), Pages: 503-512.

Broidy, Lisa, M., Nagin, Daniel, S., Tremblay, Richard, E., Bates, John,E., Brame, Bobby., Dodge, Kenneth, A., Fergusson, David., Horwood, John,L., Loeber, Rolf., Laird, Robert., Lynam,Donald,R., Moffitt, Terrie, E., Pettit, Gregory,S., Vitaro, Frank. (2003). Developmental psychology, Vol 39(2), 222-245.

Coder, C, R., Motta, J, A., Flay, B, R., Levy, S (2000). The relationship between neighbourhood danger and childhood aggression: A test of mediational mechanisms. American Journal of Community Psychology. Vol 28: 83-103. 
Craig, R, Colder., Joshua, Mott., Susan, Levy., Brian, Flay (2000). The relation of perceived Neighbourhood danger to childhood aggression: A test of mediating mechanisms. American Journal of Community Psychology, Vol 28, issue 1, pp 83-103.

Crick, N, R., \&Grotpeter (1995). Relational Aggression, gender and Social-psychological adjustment. Child Development, 66, 710-722.

Cummings, E.M., Iannotti, R.J., Zahn-Waxler C (1989). Aggression between peers in early childhood: Individual continuity and developmental change. Child development, Vol: 60(4); 887-95.

Datta, P, P., \&Firdoush, K,A (2013). Association of aggression with socio-demographic charecteristics: A cross sectional study among rural adolescents. National Journal of Medical research, 2, (4), 442-447.

Dieter, Wolke., Sarah, Woods., Katherine, Stanford., \&Henrike, Schulz (2001). Bullying and victimization of primary school children in England and Germany: Prevalence and School factors. British Journal of Psychology, Vol 92, issue 4, pages 673-696.

Dodge K. A. (1991). The structure and function of reactive and proactive aggression. In D. J. Pepler\& K.H. Rublin (Eds), Development and treatment of childhood aggression (pp. 201-218).

Duane, E, Thomas., Karen, L, Bierman., and the conduct problems research group (2006). The impact of classroom aggression on the development of aggressive behaviour problems in children. Development and Psychopathology, Vol 18(2): 417-187.

Fawwad, Shaikh., R, G, Viveki., A, B, Halappanavar (2014). Physical and Verbal Aggressive Behavior pattern among school children in Urban area of North Karnataka: A cross sectional study. Journal of Krishna Institute of Medical Sciences University (JKIMSU), Vol.3, No.2.

Hamre, B, K., Pianta, R, C. (2001). Early teacher-child relationships and the trajectory of children's school outcomes through eighth grade. Child Development, Vol 72; 625-638.

Howley, C., strange, M., Bickel, R(2000). Research about school size and school performance in impoverished communities. ERIC Digests.

Jamie, M, Ostrov.,\& Caroline, F, Keating (2004). Gender differences in preschool aggression during free paly and structured interactions: An observational study. Social Development. Vol 13, issue 2, pages 255-277.

Karen, M, Bentley (1996). Bully and victim problems in elementary schools and student's beliefs about aggression. Canadian Journal of School Psychology. Vol 11 No 2, 153-165.

Kellam, S, G., Ling, X., Merisca, R., Brown, C, H., Ialongo, N (1998). The effect of the level of aggression in the first grade classroom on the course and malleability of aggressive behaviour in the middle school. Development and Psychopathology, Vol-10: 165-185.

Kellam, S,G., Ling, X., Merisca, R., Brown, C,H., Ialongo, N(1998). The effect of the level of aggression in the first grade classroom on the course and malleability of aggressive behaviour in Middle school. Development and Psychopathology. Vol 10; 165-185.

(c) The International Journal of Indian Psychology, ISSN 2348-5396 (e)| ISSN: 2349-3429 (p) | 175 
Kenneth, A, Dodge., Gregory, S, Pettit., \& John, Bates (1994). Socialization mediators of the relation between socioeconomic status and child conduct problems. Child Development, Vol 65, issue 2, pages 649-665.

Kirsti, M, J, Lagerspetz., Kaj, Bjorkqvist., \&Tarja, Peltonen (1988). Is indirect aggression typical of females? Gender differences in aggressiveness in 11-12 year old children. Aggressive Behaviour, Vol 14, issue 6, pages 403-414.

Lochman, J. E., Tammy Barry, Nicole Powell, Laura Young. (2009). Anger and Aggression New York: Guildford press.

Marina, Camodeca., Frits, A, Goossens., Mark, Meerum, Terwogt., \& Carlo, Schuengel (2002). Bullying and victimization among school-age children: Stability and links to proactive and reactive aggression. Social Development, vol 11, issue 3, pages 332-345.

Noel, A, Card., Brian, D, Stucky, Gita, M, Sawalani.,\& Todd, D, Little (2008). Direct and indirect aggression during childhood and adolescence: A meta-Analytical review of gender differences, inter correlations, and Relations to Maladjustment. Child Development, Vol 79, Issue 5, pages: 1185-1229.

Olewus, D (1991). Bully/Victim problems in school children: Basic facts and effects of a school based intervention program. The development and treatment of childhood aggression (pp: 411-448).

Ounsted, M.K., \& Simons, C.D (1978). The first-born child: Toddlers’ problems. Developmental medicine \&child neurology, 20, 710-719.

Pellegrini, Antony, D., Bartini, Maria., Brooks, Fred (1999). School bullies and aggressive victims: Factors relating to group affiliation and victimization in early adolescence. Journal of Educational Psychology, Vol 91(2), 216-224.

Pepler, D., Craig, W., Charach, A\& Zeigler, S (1993). A school based anti-bullying intervention: Preliminary evaluation. Understanding and managing bullying, (pp. 76-91).

Perry, K, E., Weinstein, R, S (1998). The social context of early schooling and children's adjustment. Education Psychologists. Vol 33; 177-194.

Richard, Thompson., Jiyoung, Kim, Tabone., Alan, J, Litrownik., Ernestine, C, Briggs., Jon, M, Hussey., Diana, J, English., Howard, Dubowitz (2011).Early adolescent risk behavior outcomes of childhood externalizing behavior trajectories. The journal of early adolescence, Vol-31: 234-257.

Richard, Thompson.,Jiyoung, Kim, Tabone., Alan, J, Litrownik., Ernestine, C, Briggs., Jon, M, Hussey., Diana, J, English., Howard, Dubowitz(2011). Early adolescent risk behaviour outcomes of childhood externalizing behavioural trajectories. The journal of early adolescence, vol -31, 234-257.

Rutter, M (1983). School effects on pupil progress: Research findings and policy implications. Child Development. Vol 54: 1-29.

Schaeffer, C. M.,Petras, H.,Ialongo, N., Podusko, J.,\&Kellam,S.(2003). Modeling growth in boys' aggressive behaviour across elementary school: Links to later criminal 
involvement, conduct disorder, and antisocial personality disorder. Development Psychology, 39, 1020-1035.

Sheppard. G. Kellam., Xiange, Ling., Rolande, Merisca, C., Hendricks, Brown., Nick, Ialongo(1998). The effect of the level of aggression in the first grade on the course and malleability of aggressive behaviors into middle school. Development and Psychopathology. Volume/ Issue 02. Pp 165-185

Stephenson, P., Smith, D (1989). Bullying in the junior school. In: Tattum, D., Lane, D editors. Bullying in schools. Stroke on Trent: Trentham; 1989. Pp. 45-59.

T. R., Nansel., M. Overpeck., R. S., Pilla., W. J. Ruan (2001). Bullying behaviors among US youth: Prevalance and association with psychosocial adjustment. Jama 285.16: 20942100.

Tremblay R. E., Daniel S., Nagin J., Seguin R., Zoccolilillo M., Zelazo P. D., Boivon M., Perusse D., Japel C (2004). Physical Aggression during early childhood: Trajectories and Predictors. Pediatrics, 114, 43-50.

Tremblay, R, E (2000). The development of aggressive behaviour during childhood: What we learnt in the past century? International Journal of Behavioural Development, Vol: 24, 129-141.

Wendy, M, Craig (1997). The relationship among Bullying, Victimization, Depression, Anxiety, and Aggression in Elementary school children. Journal of personality and individual differences, vol 24, no 1, pp. 123-130

Werner, N.E, \& Crick, N.R (2004). Maladaptive peer relationships and the development of relational and physical aggression during middle childhood. Social Development, 13, 495-514.

How to cite this article: M Murlidhar, S Shastri (2016), Aggressive Behaviour among Elementary School Children in Bangalore: A Study on Gender and Grade Differences, International Journal of Indian Psychology, Volume 3, Issue 4, No. 63, ISSN 2348-5396 (e), ISSN: 2349-3429 (p), DIP: 18.01.111/20160304, ISBN: 978-1-365-32518-2

(c) The International Journal of Indian Psychology, ISSN 2348-5396 (e)| ISSN: 2349-3429 (p) | 177 